\title{
First Evidence of Hantavirus in Central Iran as an Emerging Viral Disease
}

\author{
Sadegh Chinikar ${ }^{*}$, Abbas Ali Javadi2*, Arash Hajiannia², Behroz Ataei2\#, Tahmineh Jalali', \\ Sahar Khakifirouz ${ }^{1}$, Norbert Nowotny ${ }^{3,4}$, Jonas Schmidt-Chanasit ${ }^{5}$, \\ Nariman Shahhosseini ${ }^{1,5}$ \\ ${ }^{1}$ Arboviruses and Viral Haemorrhagic Fevers Laboratory (National Ref. Lab), Department of Virology, Pasteur \\ Institute of Iran, Tehran, Iran \\ ${ }^{2}$ Infectious Diseases and Tropical Medicine Research Center, Isfahan University of Medical Sciences, Isfahan, \\ Iran \\ ${ }^{3}$ Institute of Virology, University of Veterinary Medicine, Vienna, Austria \\ ${ }^{4}$ Department of Microbiology and Immunology, College of Medicine and Health Sciences, Sultan Qaboos \\ University, Muscat, Oman \\ ${ }^{5}$ WHO Collaborating Centre for Arbovirus and Haemorrhagic Fever Reference and Research, Department of \\ Virology, Bernhard Nocht Institute for Tropical Medicine, Hamburg, Germany \\ Email: ${ }^{*}$ behrouzataei@chmail.ir
}

Received 21 July 2014; revised 21 August 2014; accepted 18 September 2014

Copyright (C) 2014 by authors and Scientific Research Publishing Inc.

This work is licensed under the Creative Commons Attribution International License (CC BY). http://creativecommons.org/licenses/by/4.0/

c) (i) Open Access

\begin{abstract}
Hantavirus is a zoonosis transmitted from rodents to humans. Asymptomatic infected rodents can secrete hantaviruses in the urine, feces, and saliva. The main route of infection transmission to human is aerosols contaminated with the virus. This study was designed to evaluate the serological and molecular prevalence of hantavirus as an emerging zoonoses disease among street sweepers in Isfahan province, central Iran. Serum samples from 200 street sweepers in healthy condition and those with recent renal failure were tested by ELISA (IgM and IgG). Molecular analysis was subsequently applied for IgM positive cases. From these samples, $9(4.5 \%)$ were positive, of which $2(22.22 \%)$ were positive for both IgM and RT-PCR, while $7(77.77 \%)$ were positive for IgG. The mean age and work experience of the positive cases were 39.7 and 11.5 respectively. According to our observations, all positive cases reported prevalence of rodents in their work place. The logistic regression test showed that the age and work experience were not risk factors for being positive, but prevalence of rodents in work place was a risk factor for being positive, when compared with negative cases. This is the first comprehensive study on the prevalence of hantavirus with positive results coming from Iranian population, which can raise the public awareness for the hantavirus infections as a public health threat.
\end{abstract}

\footnotetext{
"These two authors contributed equally to this work as joint first authors.

"Corresponding author.
}

How to cite this paper: Chinikar, S., Javadi, A.A, Hajiannia, A., Ataei, B., Jalali, T., Khakifirouz, S., Nowotny, N., SchmidtChanasit, J. and Shahhosseini, N. (2014) First Evidence of Hantavirus in Central Iran as an Emerging Viral Disease. Advances in Infectious Diseases, 4, 173-177. http://dx.doi.org/10.4236/aid.2014.44024 


\section{Keywords}

\section{Hantavirus, Emergence Zoonoses, Rodent, Arboviruses, Iran}

\section{Introduction}

Hantaviruses are members of the genus Hantavirus of the family Bunyaviridae. Hantaviruses are enveloped, single-stranded, negative-sensed and tri-segmented RNA viruses. In contrast to the other members of the family, arthropod vectors, hantaviruses generally chronically infect rodents. Hantaviruses have co-evolved with their rodent hosts through millions of years and each hantavirus has its own specific rodent host species [1].

Human infection with hantaviruses have been associated with two main diseases. The diseases in the Old World called Hemorrhagic Fever with Renal Syndrome (HFRS) with annual estimate of 150,000 to 200,000 occurrence are caused by Myodes-, Rattus-, and Apodemus-borne hantaviruses [1]. HFRS cases mainly have been reported from China (with more than half of global cases), Russia, Korea, Japan, Finland, Sweden, Bulgaria, Greece, Hungary, France, and the Balkan countries [2]. Clinical presentation of HFRS consists of sudden fever, severe lumbalgia, acute renal failure (ARF) and particular thrombocytopenia. Moreover, it should be noted that the majority of human hantavirus infections have no vivid clinical symptoms and may appear to be uncharacteristic. This property makes the diagnosis of hantavirus infections difficult, especially in regions where the disease is not endemic [3]. Death rates range from less than $0.1 \%$ for HFRS caused by Puumala virus to approximately $5 \%$ to $10 \%$ for HFRS caused by Hantaan virus. Most patients with HFRS recover completely, but sever complications may develop [4].

The disease in the New World called Hantavirus Pulmonary Syndrome (HPS) or hantavirus cardiopulmonary syndrome (HCPS) is caused by the sigmodontine-borne hantaviruses [5]. HPS occurs mainly in the USA and Canada and has a death rate of $40 \%$ and/or $60 \%$ in some outbreaks. In spite of disparity in geographical distribution and illnesses, the Old World and New World hantaviruses have similarities in the organizations of their nucleic sequences and their life cycles [2] [6].

Till now, over 21 hantaviruses have been detected. Several hantaviruses may remain undiscovered, since in many countries, hantaviral infections are likely to go undetected and not reported, especially in Africa, the Middle East, and the Indian subcontinent [5].

Hantavirus is a zoonosis transmitted from rodents to humans. Asymptomatic infected rodents can secrete hantaviruses in the urine, feces, and saliva. The main route of infection transmission to human, as incidental hosts, is aerosols contaminated with the virus. Also, bites by infected rodents or exposure to broken skin or mucous membranes may represent alternative routes. Although specific risk factors are poorly defined, persons of lower socioeconomic status, who are engaging in activities that bring them in closer contact with rodents and/or their excretions may be at a higher risk for infection [7] [8].

Epidemiological investigations have shown that farmers, soldiers, and rural inhabitants are high-risk groups for hantavirus. Initially, it was believed that hantavirus occurred only in rural areas, but careful consideration showed that some hantavirus infections could also happen in urbanized cities and in many parts of the world [5].

From 2008 to 2009, to find the first evidence of hantavirus in Iran, 10 serum samples of patients with acute renal failure and thrombocytopenia with no obvious causative reason were collected from nephrology and dialysis unit of Imam Hossein Hospital in Tehran, capital of Iran. All samples were analyzed for antibodies against hantavirus by Immunofluorescent assay (IFA), but no seropositive cases were found.

As the epidemiology of hantavirus in Iran is not clear, this study was designed to evaluate the prevalence of hantavirus in human cases in Isfahan province, central Iran. In this regard, street sweepers were selected as the study group, because of their high inhalation probability of contaminated aerosols with rodents' feces as the main reservoirs of hantavirus.

\section{Methods}

\subsection{Sampling}

200 serum samples from central Iran were collected from street sweeper man with acute renal failure, fever and thrombocytopenia in early-phase serum specimens and those in healthy conditions, both groups with possible 
exposure to rodents in March 2013. After completion of questionnaires, their specimens were submitted to Arboviruses and Viral Haemorrhagic Fevers Laboratory (National Reference Laboratory) of the Pasteur Institute of Iran. This laboratory is responsible for surveillance, rapid diagnosis and awareness of VHFs, including CrimeanCongo Hemorrhagic Fever Virus [9] [10], Dengue virus [11], West Nile virus [12], Rift Valley Fever virus [13] and Hanta virus in Iran.

\subsection{Serological Assay}

The most common tools for the laboratory diagnosis of hantavirus infections are serological tests, which detect IgM and/or IgG antibodies against hantaviral antigens in serum. By far indirect IgG and IgM Enzyme-linked Immunosorbent Assays (ELISAs) as well as IgM capture ELISAs are the most reliable and routine serological assay for hantaviruses.

IgM: Serum samples were diluted (1/100) by adding $1 \mu \mathrm{l}$ serum samples to $100 \mu \mathrm{l}$ of sample dilution. Subsequently, $100 \mu \mathrm{l}$ of the 1/100 dilutions of serum samples, $100 \mu \mathrm{l}$ of positive control, $100 \mu \mathrm{l}$ of cut off and 100 $\mu \mathrm{l}$ of negative control were added into the corresponding wells and incubated at $37^{\circ} \mathrm{C}$ for $60 \mathrm{~min}$. The following steps were undertaken according to the manufacturer's instructions of the Anti-Hanta Virus Pool ELISA IgM kit (Cat no. El 278h-9601-1 M, EUROIMMUN) [14]-[16].

IgG: $100 \mu \mathrm{l}$ of the $1 / 100$ dilutions of serum samples, $100 \mu \mathrm{l}$ of positive control, $100 \mu \mathrm{l}$ of cut off and $100 \mu \mathrm{l}$ of negative control were added into the corresponding wells and incubated at $37^{\circ} \mathrm{C}$ for $60 \mathrm{~min}$. The subsequent steps were undertaken according to the manufacturer's instruction of the Anti-Hanta Virus Pool ELISA IgG kit (Cat no. El 278h-9601-1 G, EUROIMMUN) [14]-[16].

\subsection{Molecular Assay}

Performing RT-PCR on acute phase serum specimens during the first 10 days of illness can be positive. All the samples found IgM positive by ELISA were further tested by RT-PCR. For this purpose, viral RNA was extracted from $140 \mu \mathrm{l}$ of serum samples using a QIAamp RNA kit according to the instructions of the manufacturer (Cat No. 52906, Qiagen GmbH, Hilden, Germany). Extracted RNA was stored at $-80^{\circ} \mathrm{C}$. Then, extracted RNA was analyzed by one-step RT-PCR using the following primers for S segment of virus genome: KPS1 (3'-ATTG ATGAACCTACCAGGACAGACAGC-5') and KPS2 (3'-ATAAACAAGCATGTTGGTGGACA-5'), and the following primers for M segment: HS1 (3'-ACCTGTCAATTTGGTGACCC-5') and HS2 (3'-TCACAAGCCTT TATTGATGT-5') [17].

\subsection{Statistical Analysis}

Data analysis was performed by SPSS (version 16, SPSS Inc, Chicago) software package. Descriptive statistics (i.e. frequencies and percentages) were used to summarize the quantitative variables. To evaluate the risk factors for being positive, the logistic regression test was used. $P$-values $<0.05$ were considered significant.

\section{Results}

In this study, serum samples from 200 cases, all from Isfahan province in central Iran, were tested. From these samples, 9 (4.5\%) were positive, of which 2 (22.22\%) were positive for both IgM and RT-PCR among acute renal failure patients, while 7 (77.77\%) were positive for IgG among healthy participants. The mean age and work experience of the positive cases were 39.7 and 11.5 respectively (Table 1 ).

Among the positive cases, 4 (44.44\%) cases reported high prevalence of rodent in work place, 3 (33.33\%) cases reported middle prevalence of rodent in work place and $2(22.22 \%)$ reported low prevalence of rodent prevalence in work place. All cases are survived.

The logistic regression test showed that the age and work experience were not risk factor for being positive, but prevalence of rodents in work place was a risk factor for being positive, when compared with negative cases.

\section{Discussion}

Hantaviruses are emerging viruses that cause hemorrhagic fever with renal syndrome (HFRS) in Asia and Europe and hantavirus cardiopulmonary syndrome in North and South America. The global distribution of rodents, 
Table 1. Summary of patients with positive hantavirus in central Iran.

\begin{tabular}{ccccccc}
\hline No. & Age & Work Experience & Prevalence of Rodent in Work Place & IgM & IgG & RT-PCR \\
\hline 1 & 31 & 8 & Middle & Neg & Pos & Neg \\
2 & 46 & 22 & High & Neg & Pos & Neg \\
3 & 30 & 8 & Low & Neg & Pos & Neg \\
4 & 39 & 15 & Low & Pos & Neg & Pos \\
5 & 25 & 2 & High & Neg & Pos & Neg \\
6 & 40 & 22 & Middle & Pos & Neg & Pos \\
7 & 51 & 9 & Middle & Neg & Pos & Neg \\
8 & 50 & 8 & High & Neg & Pos & Neg \\
9 & 46 & 10 & High & Neg & Pos & Neg \\
\hline
\end{tabular}

the main reservoirs of hantaviruses, provides great disease-causing potential. Hantavirus infection is a grave public health concern in Asia, Europe, and the Americas wherever rodents of the family Muridae are present, and they have been identified in rodents of the subfamilies Murinae, Arvicolinae, and Sigmodontinae [18].

Previous studies demonstrated that the aerosol route of infection is undoubtedly the most common mean of transmission among rodents and to humans. Epidemiologic studies have linked virus exposure to activities like farm work, threshing, sleeping on the ground, and military exercises. Also, indoor exposure may happen when field rodents attack or settle in a home during cold weather. Hantavirus infection is mainly seen in persons of lower socioeconomic status because poorer housing conditions and farming activities favor closer contact between humans and rodents [2].

In the neighbouring countries of Iran, It seems that the most cases have been reported from Turkey [15] [19]. As part of our ongoing surveillance on viral zoonoses in Iran, human sera from street sweepers were collected in Isfahan province. This is the first comprehensive study on the prevalence of hantavirus infection coming from Iranian population. The prevalence of antibodies to hantavirus among the 200 human sera was $4.5 \%$.

The report of two molecular positive cases in this study should alert physicians that hantavirus infection should be noticed in the differential diagnosis of patients who have high fever and thrombocytopenia with negative laboratory results for other endemic viral hemorrhagic fevers like Crimean-Congo hemorrhagic fever in Iran.

According to our observations, all positive cases reported prevalence of rodent in their work place. Although two patients declared low rodent prevalence in their work place, this infection route cannot be excluded as street sweepers spent most of their work time with rubbish which likely were contaminated with rodents' feces and urine. Several studies have discussed the role of indirect (aerosols) and direct (physical contacts) transmission modes in hantavirus dynamics. Since the amount of saliva secreted into the environment is not very considerable, direct contacts are needed for an efficient transmission via saliva. In contrast, shedding of the virus in urine and feces would escalate the probability of indirect transmission, since the amounts of secreted urine and feces exceed that of saliva. As a result, indirect transmission makes the transmission rate less dependent on the rodent density and enhances the persistence of virus in the rodent population. Also, some studies emphasize the significance of hantavirus survival outside the rodent host for transmission dynamics and human risk [8]. Given gender prevalence of hantavirus infection among population in this study, all collected cases in our study were men, because sweeping is being performed almost exclusively by men in Iran.

\section{Conclusion}

There is no previous published data on hantavirus infection in Iran and laboratory diagnoses or clinical cases are not much known in Iran. Thus, general physicians are probably unaware about the aetiology of hantavirus. This proposes that there could be circulation of the hantaviruses in the Iranian population. A major objective of our study was to raise the public awareness for the hantavirus infections as a public health threat and to include hantavirus in surveillance studies in Iran. In future studies, priority should also be given to Sero-epidemiologic studies in human and rodent population in different geographical region of Iran in order to define the true preva- 
lence and risk factors for acquiring hantavirus infection.

\section{Conflict of Interest}

We declare no conflict of interest.

\section{Acknowledgements}

We thank all of the members of the Arboviruses and Viral Hemorrhagic Fevers Laboratory (National Reference Laboratory), Pasteur Institute of Iran.

\section{References}

[1] Peters, C. and Khan, A.S. (2002) Hantavirus Pulmonary Syndrome: The New American Hemorrhagic Fever. Clinical Infectious Diseases, 34, 1224-1231. http://dx.doi.org/10.1086/339864

[2] Schmaljohn, C. and Hjelle, B. (1997) Hantaviruses: A Global Disease Problem. Emerging Infectious Diseases, 3, 95104. http://dx.doi.org/10.3201/eid0302.970202

[3] Clement, J.P. (2003) Hantavirus. Antiviral Research, 57, 121-127. http://dx.doi.org/10.1016/S0166-3542(02)00205-X

[4] Sarıüzel, N., Hofmann, J., Canpolat, A.T., et al. (2012) Dobrava Hantavirus Infection Complicated by Panhypopituitarism, Istanbul, Turkey, 2010. Emerging Infectious Diseases, 18, 1180-1183. http://dx.doi.org/10.3201/eid1807.111746

[5] Jonsson, C.B., Figueiredo, L.T.M. and Vapalahti, O. (2010) A Global Perspective on Hantavirus Ecology, Epidemiology, and Disease. Clinical Microbiology Reviews, 23, 412-441. http://dx.doi.org/10.1128/CMR.00062-09

[6] Frey, M.T., Vial, P.C., Castillo, C.H., et al. (2003) Hantavirus Prevalence in the IX Region of Chile. Emerging Infectious Diseases, 9, 827-832. http://dx.doi.org/10.3201/eid0907.020587

[7] Jay, M., Ascher, M.S., Chomel, B.B., et al. (1997) Seroepidemiologic Studies of Hantavirus Infection among Wild Rodents in California. Emerging Infectious Diseases, 3, 183-190. http://dx.doi.org/10.3201/eid0302.970213

[8] Kallio, E.R., Klingström, J., Gustafsson, E., et al. (2006) Prolonged Survival of Puumala Hantavirus Outside the Host: Evidence for Indirect Transmission via the Environment. Journal of General Virology, 87, 2127-2134. http://dx.doi.org/10.1099/vir.0.81643-0

[9] Chinikar, S., Shayesteh, M., Khakifirouz, S., et al. (2013) Nosocomial Infection of Crimean-Congo Haemorrhagic Fever in Eastern Iran: Case Report. Travel Medicine and Infectious Disease, 11, 252-255. http://dx.doi.org/10.1016/j.tmaid.2012.11.009

[10] Chinikar, S., Shah-Hosseini, N., Bouzari, S., et al. (2013) New Circulating Genomic Variant of Crimean-Congo Hemorrhagic Fever Virus in Iran, Archives of Virology, 158, 1085-1088. http://dx.doi.org/10.1007/s00705-012-1588-0

[11] Chinikar, S., Ghiasi, S. M., Shah-Hosseini, N., et al. (2013) Preliminary Study of Dengue Virus Infection in Iran. Travel Medicine and Infectious Disease, 11, 166-169. http://dx.doi.org/10.1016/j.tmaid.2012.10.001

[12] Chinikar, S., Shah-Hosseini, N., Mostafavi, E., et al. (2013) Seroprevalence of West Nile Virus in Iran. Vector-Borne and Zoonotic Diseases, 13, 586-589. http://dx.doi.org/10.1089/vbz.2012.1207

[13] Chinikar, S., Shah-Hosseini, N., Mostafavi, E., Jalali, T. and Fooks, A.R. (2013) Surveillance of Rift Valley Fever in Iran between 2001 and 2011. All Results Journals, 4, 16-18.

[14] Rovida, F., Percivalle, E., Sarasini, A., Chichino, G. and Baldanti, F. (2013) Imported Hantavirus Cardiopulmonary Syndrome in an Italian Traveller Returning from Cuba. The New Microbiologica, 36, 103-105.

[15] Oncul, O., Atalay, Y., Onem, Y., et al. (2011) Hantavirus Infection in Istanbul, Turkey. Emerging Infectious Diseases, 17, 303-304. http://dx.doi.org/10.3201/eid1702.100663

[16] Escadafal, C., Avšič-Županc, T., Vapalahti, O., et al. (2012) Second External Quality Assurance Study for the Serological Diagnosis of Hantaviruses in Europe. PLoS Neglected Tropical Diseases, 6, e1607.

[17] Hofmann, J., Meisel, H., Klempa, B., et al. (2008) Hantavirus Outbreak, Germany, 2007. Emerging Infectious Diseases, 14, 850-852. http://dx.doi.org/10.3201/eid1405.071533

[18] Heyman, P., Cochez, C., Korukluoğlu, G., et al. (2011) Bridging Continents: Hantaviruses of Europe and Asia Minor. Türk Hijyen ve Deneysel Biyoloji Dergisi, 68, 41-48. http://dx.doi.org/10.5505/TurkHijyen.2011.33254

[19] Gozalan, A., Kalaycioglu, H., Uyar, Y., et al. (2013) Human Puumala and Dobrava Hantavirus Infections in the Black Sea Region of Turkey: A Cross-Sectional Study. Vector-Borne and Zoonotic Diseases, 13, 111-118. http://dx.doi.org/10.1089/vbz.2011.0939 
Scientific Research Publishing (SCIRP) is one of the largest Open Access journal publishers. It is currently publishing more than 200 open access, online, peer-reviewed journals covering a wide range of academic disciplines. SCIRP serves the worldwide academic communities and contributes to the progress and application of science with its publication.

Other selected journals from SCIRP are listed as below. Submit your manuscript to us via either submit@scirp.org or Online Submission Portal.
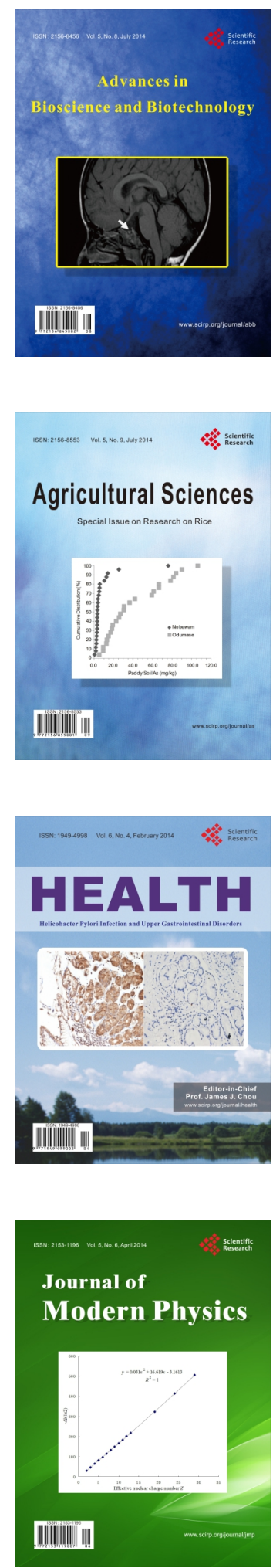
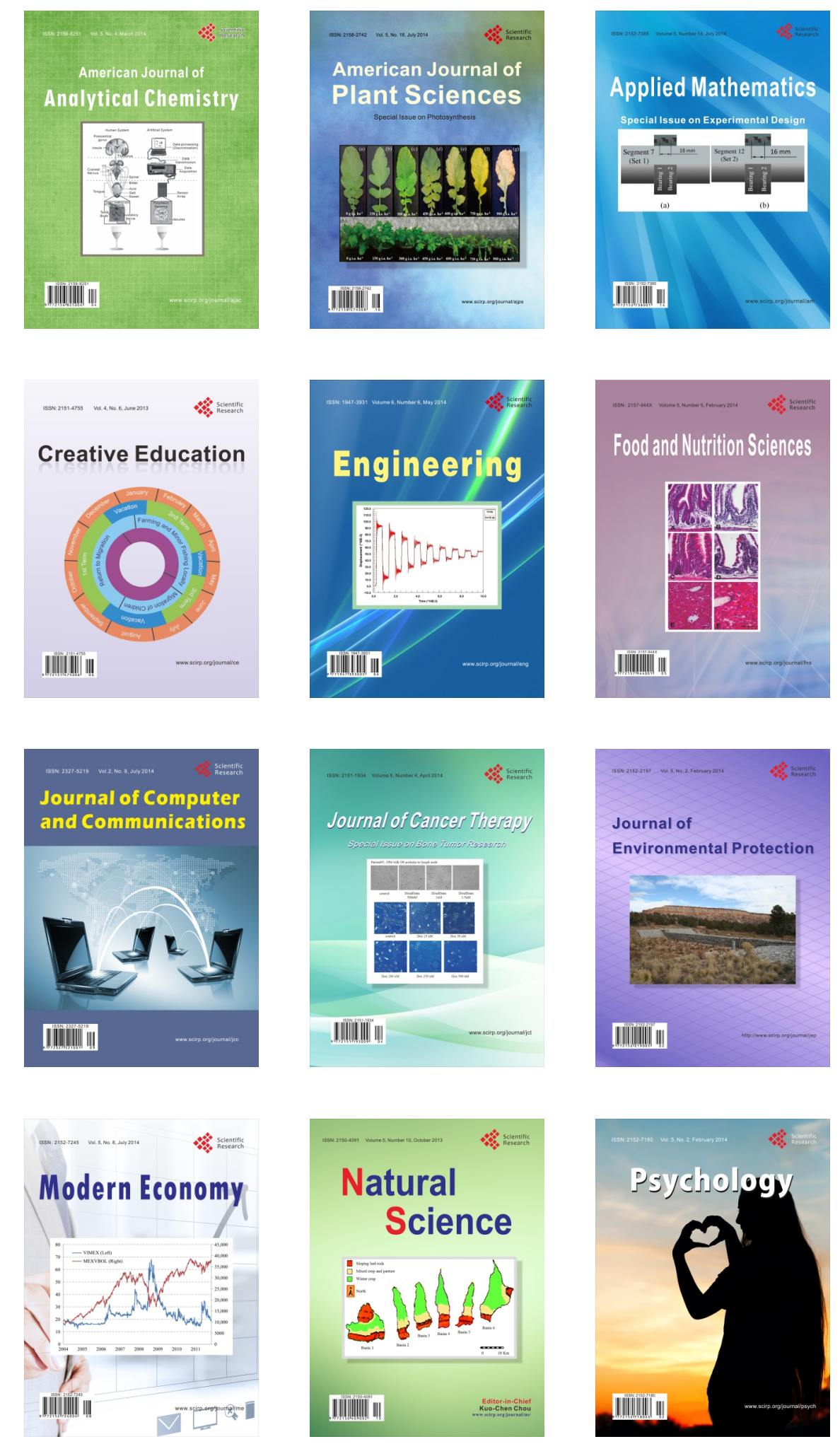